\title{
Which aspects of breathing during sleep influence the overnight fall of blood pressure in a community population?
}

\author{
J R Stradling, C Barbour, J Glennon, B A Langford, J H Crosby
}

\begin{abstract}
Background-Obstructive sleep apnoea (OSA) causes recurrent rises in blood pressure during sleep, and recent community surveys have suggested a link between mild OSA and diurnal hypertension. The fact that OSA and hypertension share some risk factors, as well as problems accurately quantifying OSA severity, have diluted the power of such studies. This study tries to circumvent some of these problems by measuring the overnight change in blood pressure and relating it to relevant measures of the severity of upper
\end{abstract} airway obstruction on the same night.

Methods-Men born between 1930 and 1960 and their wives living in a market town north of Oxford were identified from a GP practice register. Enough couples were recruited to provide approximately 10 (20 individuals) per year of birth. Subjects were visited at home where a questionnairewasadministered, anthropometric measurements made, blood pressures taken (including by the subject), and sensors applied for a subsequent overnight sleep study. The sleep study measured indices of hypoxia, snoring, autonomic arousal, degree of respiratory effort; the last two of these derived from measurements of pulse transit time (indirect beat to beat blood pressure). After waking the following morning, the subjects took their own blood pressures again. Results-Data were available from 224 couples (448 subjects). On average, systolic $\mathrm{BP}$ fell $8 \mathrm{~mm} \mathrm{Hg}$ from evening to morning. Only hypoxic dips $\left(>4 \% \mathrm{SaO}_{2}\right.$ $\mathrm{dips} / \mathrm{h}$ ) and the measure of degree of respiratory effort were significant independent predictors of this overnight change in systolic $\mathrm{BP}$, together accounting for $7-10 \%$ of the variation $(p<0.0001)$. Dividing the subjects into quartiles according to the respiratory effort overnight showed a progressive reduction in the fall of systolic BP overnight: 13.6, 10.8, 7.3, and $5.6 \mathrm{~mm} \mathrm{Hg}$, lowest to highest quartiles.

Conclusions-This study suggests that increased respiratory effort during sleep (seen in OSA and related syndromes of increased upper airway resistance during sleep) offsets the normal fall in BP that occurs overnight, even within this community population. This may be one of the mechanisms by which hypertension is carried over into the waking hours in patients with OSA.

(Thorax 2000;55:393-398)

Keywords: respiratory effort; obstructive sleep apnoea; hypertension

Obstructive sleep apnoea (OSA) and its variant (upper airways resistance syndrome) cause recurrent arousals and thus rises in blood pressure (BP) during sleep and, in addition, may be independently responsible for increases in awake BP. Proving the latter has been difficult because of the similarity of risk factors for developing both OSA and diurnal hypertension - for example, upper body obesity and alcohol consumption. Recent work has suggested that, even in a community population, minor degrees of sleep apnoea may be an independent risk factor for hypertension, ${ }^{12}$ although complete disentanglement of the risk factors common to both conditions is almost impossible. In addition, sleep apnoea is usually assessed from a one night sleep study despite considerable night to night variation, particularly in the middle of the disease spectrum. ${ }^{3}$ This means that an inconsistent and possibly unrepresentative one night measure is being used to try to quantify a potential cardiovascular risk that extends back over time, probably for several years. Thus, there will be significant dilution of any causal link between current sleep apnoea and a potential consequence, such as diurnal hypertension. Furthermore, if the conventional index of sleep apnoea, apnoea hypopnoea index (AHI), poorly represents the precise aspect of the disease that may be responsible for cardiovascular consequences, then the situation is even worse. These problems increase the chance that an index such as AHI may actually code for some other more powerful risk factor such as upper body obesity, rather than being a measure of sleep apnoea as intended.

There is a need for data that approach the problem of causality in a way that may be able to bypass the issue of the confounding variables and/or the night to night variation. For example, very closely matched case control studies, randomised placebo controlled trials of treating OSA on BP, and studies looking at overnight changes in $\mathrm{BP}$ in relation to the extent of the OSA on that particular night. This study uses this latter approach.

The evidence is convincing that the end of each apnoea is accompanied by a surge in blood pressure when the arousal process briefly 
activates the brainstem cardiovascular control centres with a transient resetting of the baroreflex. ${ }^{56}$ However, there is no convincing evidence as to the stimulus that may be present during periods of OSA that might lead to a longer term carryover of hypertension into the waking hours. Increased sympathetic tone is a possible intermediary ${ }^{7}$ but there are at least three possible candidates for its initiation, acting alone or in concert-namely, hypoxia, recurrent arousal, and increased inspiratory drive with greater subatmospheric pleural pressure swings during the periods of actual obstructions (whether partial or complete).

This study looks at the relationship between overnight measures of these three potential stimuli and the change in evening to morning blood pressure over the same night in a community based population of men and women.

\section{Methods}

SUBJECTS

Potential subjects for this study were identified from the register of a general practice serving approximately one third of the population of Bicester, a market town 10 miles north of Oxford. The practice computer could generate lists of husband and wife pairs according to year of birth of the husband. Each couple was then written to by their GP inviting them to take part in the study. Years of birth between 1930 and 1960 were selected randomly for sequential study over the 3.5 year recruitment period. Enough couples were contacted to provide approximately 10 per year of birth (20 individuals) to be studied.

\section{TECHNIQUES}

Sleep studies

Sleep studies were performed in the subjects' own homes using RM50 portable monitors (Parametric Recorders, London, UK). These devices record for eight hours and can be programmed to turn on and off at particular times (usually 23.00 and 07.00 hours, respectively). The RM50 records oxygen saturation from a finger probe, snoring via a throat microphone, body position via a sensor in a chest box (held on by one chest band), chest movements, heart rate (from three ECG electrodes), and pulse transit time. The latter is the time delay between the ECG R wave and the arrival of the pulse wave at the finger detected from the transmittance signal of the oximeter probe. This value is typically about $250 \mathrm{~ms}$ and varies inversely with blood pressure. As BP falls, tension in the arterial wall falls and the pulse transit time increases; and vice versa. Thus, beat to beat measures of pulse transit time provide an estimate of beat to beat changes in blood pressure. $^{89}$

Analysis of these signals for this study provided the following derivatives: the number of $>4 \%$ dips in oxygen saturation per hour of study, ${ }^{10}$ minimum and mean oxygen saturation overnight, numbers of snores per hour of study, number of rises in blood pressure per hour of study, ${ }^{11}{ }^{12}$ number of heart rate rises per hour of study (using either a six or $10 \mathrm{bpm}$ threshold), ${ }^{11}$ and the average fall in blood pressure due to each breath (pulsus paradoxus) across the whole study. ${ }^{13}{ }^{14}$ The exact methods used to derive these indices have been described elsewhere. ${ }^{15}$ Essentially, a fall in pulse transit time of $>15 \mathrm{~ms}$ (an approximate rise in BP of $15 \mathrm{~mm} \mathrm{Hg}$ ) over a time course of 5-45 seconds is classified as a "blood pressure arousal". This particular threshold of $15 \mathrm{~ms}$ derives from previous work in normal subjects and equates approximately to a three second speeding of the EEG in response to an auditory stimulus delivered during non-REM sleep. ${ }^{11}$ These "blood pressure arousals" correlate well with EEG based definitions of arousal, and also predict daytime sleepiness as effectively as EEG arousals. ${ }^{1215} 16$ Oscillations in pulse transit time over a time course of $0.7-4.5$ seconds reflect respiratory efforts and have been used by other workers to differentiate central from obstructive apnoeas. ${ }^{17}$ Thus, the units for the latter are in milliseconds and the overnight average of all the breaths can be calculated.

\section{Blood pressure}

Evening blood pressures were measured at least in triplicate using the UA-751 auto inflation monitor (PMS Instruments, Maidenhead, UK). This device uses the oscillotonometric method and has been well validated. ${ }^{18}$ Blood pressures were taken by the nurse at about 20.30 hours after administration of the questionnaire (which took about 20 minutes) with the subject sitting in a chair throughout; these values are subsequently referred to as the "casual BP". Remaining seated, the subjects were then shown how to use the BP device. They took their own BP at least three times until demonstrating proficiency, as judged by the nurse and based on obtaining three consistent readings. These figures are subsequently referred to as the "subject measured evening BP". Subjects took their BP again three times immediately on waking the following morning, before getting out of bed and whilst sitting on the side of the bed. The results were printed using the internal printer and subsequently referred to as the "subject measured morning BP". The difference between the mean of the three evening and morning BPs, both taken by the subject, was used as a measure of the subject's overnight change in $\mathrm{BP}$.

Questionnaire and anthropometric measurements The questionnaire administered by the nurse contained questions on sleep, sleepiness, snoring, cardiovascular disease, medication, alcohol consumption, and tobacco usage. In addition, the nurse measured neck circumference at the level of the cricothyroid membrane, waist circumference at the level of the umbilicus, height, and weight. The body mass index $\left(\mathrm{kg} / \mathrm{m}^{2}\right)$ and the waist to height ratio ${ }^{19}$ were calculated to provide indices of general and upper body obesity, respectively.

PROTOCOL

Following the identification of suitable couples, the GP with whom the man was registered 
wrote a standard letter to them explaining the purpose of the study and informing them that a nurse from the Churchill Hospital would contact them soon to discuss participation in the study. Within two weeks they were telephoned and the study explained. If they both agreed to be studied then an appointment was made to visit them in the evening. At this time the questionnaire was administered and BP measured. The anthropometric measurements were then made, followed by application of the various sensors and connection to the RM50 overnight recorder. Following testing of the RM50, the main cable to the recorder was disconnected but the sensors left in place. Subjects were instructed to reconnect the cable on retiring. The following morning, after the BP measurements by the subjects, the sensors were removed and all the equipment left for collection by the nurse.

Couples were studied together as a pair mainly for reasons of economy but also, as part of a different study, because we were interested in the possible effect of one partner's snoring on the other's sleep.

This protocol was approved by the Central Oxford research ethics committee (94.086) and funded by the Wellcome Trust (grant number 0429022).

\section{ANALYSIS OF DATA}

The RM50 sleep studies were all reviewed manually to identify approximate sleep periods using the thoracic movement channel to identify body movements. It was usually quite clear when these ceased (to be replaced by regular breathing movements only), and then when body movements returned in the morning, following arousal. In addition, periods of inadequate tracings due to disconnection of any sensors could be excluded from the analysis. If there were at least three hours of adequate recordings, these periods of assumed sleep were automatically processed to provide the derivatives described above without further manual editing.

All data were entered into a computer data file for analysis by the SAS suite of statistical

Table 1 Subject data $(n=448)$ : continuous variables

\begin{tabular}{|c|c|c|c|c|}
\hline & \multicolumn{2}{|l|}{ Men } & \multicolumn{2}{|l|}{ Women } \\
\hline & Mean & $S D$ & Mean & $S D$ \\
\hline Age (years) & 50.9 & 8.0 & 48.6 & 8.5 \\
\hline Height $(\mathrm{m})$ & 1.76 & 0.07 & 1.64 & 0.07 \\
\hline Weight $(\mathrm{kg})$ & 84.1 & 12.8 & 70.7 & 13.3 \\
\hline $\mathrm{BMI}\left(\mathrm{kg} / \mathrm{m}^{2}\right)$ & 27.2 & 3.7 & 26.3 & 4.5 \\
\hline Waist $(\mathrm{cm})$ & 97.6 & 10.4 & 84.8 & 12.1 \\
\hline Waist to height $(\mathrm{cm} / \mathrm{m})$ & 55.5 & 5.9 & 51.8 & 7.3 \\
\hline Casual evening systolic BP (mm Hg) & 134.0 & 16.7 & 127.8 & 19.2 \\
\hline Casual evening diastolic $\mathrm{BP}(\mathrm{mm} \mathrm{Hg})$ & 83.1 & 9.6 & 80.8 & 11.9 \\
\hline Subject measured evening systolic $\mathrm{BP}(\mathrm{mm} \mathrm{Hg})$ & 130.9 & 15.9 & 126.6 & 19.0 \\
\hline Subject measured evening diastolic $\mathrm{BP}(\mathrm{mm} \mathrm{Hg})$ & 81.6 & 9.1 & 79.6 & 11.0 \\
\hline Subject measured morning systolic $\mathrm{BP}(\mathrm{mm} \mathrm{Hg})$ & 123.4 & 16.0 & 117.3 & 17.5 \\
\hline Subject measured morning diastolic $\mathrm{BP}(\mathrm{mm} \mathrm{Hg})$ & 79.1 & 9.5 & 74.7 & 11.3 \\
\hline Morning to evening difference: systolic ( $\mathrm{mm} \mathrm{Hg}$ ) & -7.8 & 13.3 & -9.1 & 15.1 \\
\hline Morning to evening difference: diastolic ( $\mathrm{mm} \mathrm{Hg}$ ) & -2.6 & 9.4 & -4.8 & 9.3 \\
\hline$>4 \% \mathrm{SaO}_{2} \mathrm{dips} / \mathrm{h}$ of study & 2.47 & 4.64 & 1.17 & 2.81 \\
\hline Minimum $\mathrm{SaO}_{2}$ overnight & 89.2 & 5.7 & 90.3 & 5.7 \\
\hline Mean $\mathrm{SaO}_{2}$ overnight & 96.0 & 1.2 & 96.3 & 1.1 \\
\hline $\mathrm{BP}$ rises/h of study & 24.2 & 14.9 & 15.6 & 11.4 \\
\hline Average respiratory effort overnight (ms) & 10.6 & 3.21 & 9.97 & 2.22 \\
\hline Snores/h of study & 114 & 205 & 67.3 & 143 \\
\hline Heart rate rises $/ \mathrm{h}$ of study $(>10 \mathrm{bpm})$ & 22.6 & 18.4 & 17.8 & 12.3 \\
\hline Heart rate rises $/ \mathrm{h}$ of study $(>6 \mathrm{bpm})$ & 41.8 & 22.5 & 36.1 & 19.1 \\
\hline
\end{tabular}

software (SAS Institute Inc, Cary, NC, USA). The relationships between the change in overnight blood pressure and possible predictors were first explored with simple linear regression. Independence of any significant correlation was then proved using the type III sum of squares analysis within the general linear models procedure which tests whether a particular variable is still significantly correlated with the outcome measure of interest, even after allowing for all other measured variables first. Potentially predictive factors were then used within a multiple linear regression model with forward selection to identify the "best" predictors and model the overnight change in BP. Predictors explored were $>4 \% \mathrm{SaO}_{2} \mathrm{dips} / \mathrm{h}$, minimum overnight $\mathrm{SaO}_{2}$, mean overnight $\mathrm{SaO}_{2}, \mathrm{BP}$ rises/h, heart rate rises $/ h$, mean respiratory effort, snores $/ h$, actual systolic and diastolic BP, obesity indices, as well as the questionnaire measures of snoring, alcohol, and tobacco consumption. In addition, interactive terms using two of the three main sleep study indices were explored $(>4 \%$ $\mathrm{SaO}_{2}$ dips/h, BP arousals, and mean respiratory effort).

\section{Results}

A total of 1260 subjects (630 couples) were identified from the GP computer records as potentially suitable for the study and letters were sent. Of these, 176 couples proved uncontactable by telephone, either because they had no phone, had moved away, or never answered the telephone calls. Thus, 542 couples (1084 subjects) were contacted by telephone. Of these, 264 couples (528 subjects, $49 \%$ ) agreed to be visited at home and participate in sleep studies. Depending on the rate of refusal, new letters were sent out until about 10 couples per male year of birth selected had agreed to be studied. Of these 528 subjects, 504 had complete data on evening and morning blood pressures, but only 448 of these had complete data for all variables from the sleep study ( $41 \%$ of original contacted population). Failures were usually due to sensor displacement during sleep (ECG electrode and oximetry probe) which left less than three hours of tracing that could be analysed.

Tables 1 and 2 show the basic data from the population relevant to this study. The women were slightly younger (by about two years) as the selection of subjects was done by male date of birth. Approximately $10 \%$ of subjects were on antihypertensive medication and the average BP of this group was $147 / 86$ compared with the rest $(129 / 82)$. The hypertensive subjects were also more obese (mean body mass index (BMI) 29.1 versus 26.5).

The average fall in systolic BP from evening to morning was nearly $8 \mathrm{~mm} \mathrm{Hg}$ (diastolic nearly $3 \mathrm{~mm} \mathrm{Hg}$ ) with a considerable range (table 1).

There were, of course, many single correlations between the indices under investigation (table 3). However, multiple regression using type III sum of squares indicated that most variables, except for $>4 \% \quad \mathrm{SaO}_{2} \mathrm{dips} / \mathrm{h}$ and mean respiratory effort, did not have an 
Table 2 Subject data $(n=448)$ : discontinuous data

\begin{tabular}{|c|c|c|c|c|c|c|c|c|c|c|}
\hline & \multicolumn{5}{|l|}{ Women } & \multicolumn{5}{|l|}{ Men } \\
\hline & Grade 1 & Grade 2 & Grade 3 & Grade 4 & Grade 5 & Grade 1 & Grade 2 & Grade 3 & Grade 4 & Grade 5 \\
\hline Snoring & 28.0 & 26.5 & 20.1 & 10.8 & 14.6 & 11.5 & 18.8 & 22.4 & 15.0 & 32.3 \\
\hline Alcohol & 72.9 & 25.1 & 1.6 & 0.4 & & 59.4 & 33.5 & 5.9 & 1.2 & \\
\hline Smoking & 66.0 & 9.0 & 9.0 & 16.0 & & 68.9 & 11.5 & 7.3 & 12.3 & \\
\hline & No & & Yes & & & No & & Yes & & \\
\hline Ever had raised BP & 86.2 & & 13.8 & & & 83.5 & & 16.5 & & \\
\hline Ever had MI or angina & 96.3 & & 3.7 & & & 93.8 & & 6.2 & & \\
\hline On anti-hypertensives & 92.9 & & 7.1 & & & 87.3 & & 12.7 & & \\
\hline
\end{tabular}

Values are percentages. Snoring: $1=$ never, $2=<1$ night $/$ week, $3=1-2$ nights $/$ week, $4=3-5$ nights/week, $5=$ almost every night. Alcohol: $1=<1$ unit $/$ day, $2=1-3$ units/day, $3=4-7$ units/day, $4=>7$ units/day. Smoking: $1=$ none, $2=1-5$ cigarettes $/$ day, $3=6-15$ cigarettes $/$ day, $4=>15$ cigarettes $/$ day.

Table 3 Single correlations between sleep study indices and change in systolic and diastolic BP overnight in men and women ( $n=448)$

\begin{tabular}{|c|c|c|c|c|c|c|c|c|c|c|}
\hline & $\begin{array}{l}\mathrm{Mean} \\
\mathrm{SaO}_{2}\end{array}$ & $\begin{array}{l}\text { Minimum } \\
\mathrm{SaO}_{2}\end{array}$ & $\begin{array}{l}B P \text { rises/ } \\
h\end{array}$ & $\begin{array}{l}>10 \mathrm{bpm} \\
\text { heart rate } \\
\text { rises } / \mathrm{h}\end{array}$ & $\begin{array}{l}>6 \mathrm{bpm} \\
\text { heart rate } \\
\text { rises } / \mathrm{h}\end{array}$ & $\begin{array}{l}\text { Mean } \\
\text { respiratory } \\
\text { effort }\end{array}$ & Snores $/ h$ & Age & $\begin{array}{l}\text { Systolic BP* } \\
\text { change } \\
\text { overnight }\end{array}$ & $\begin{array}{l}\text { Diastolic } B P^{\star} \\
\text { change } \\
\text { overnight }\end{array}$ \\
\hline$>4 \% \mathrm{SaO}_{2} \operatorname{dips} / \mathrm{h}$ & -0.53 & -0.59 & 0.25 & 0.05 & 0.03 & 0.21 & 0.23 & 0.22 & 0.17 & 0.21 \\
\hline Mean $\mathrm{SaO}_{2}$ & & 0.52 & 0.16 & -0.08 & -0.04 & -0.21 & -0.19 & 0.29 & -0.09 & -0.17 \\
\hline Minimum $\mathrm{SaO}_{2}$ & & & 0.17 & -0.03 & 0.00 & -0.23 & -0.21 & 0.18 & -0.14 & -0.15 \\
\hline $\mathrm{BP}$ rises $/ \mathrm{h}$ & & & & 0.44 & 0.39 & 0.42 & 0.06 & 0.17 & 0.07 & 0.11 \\
\hline$>10 \mathrm{bpm}$ heart rate rises $/ \mathrm{h}$ & & & & & 0.92 & 0.32 & 0.00 & 0.07 & 0.12 & 0.11 \\
\hline$>6 \mathrm{bpm}$ heart rate rises $/ \mathrm{h}$ & & & & & & 0.28 & 0.00 & 0.13 & 0.10 & 0.05 \\
\hline Mean respiratory effort & & & & & & & 0.21 & 0.08 & 0.23 & 0.16 \\
\hline Snores $/ \mathrm{h}$ & & & & & & & & 0.11 & 0.03 & 0.03 \\
\hline Age & & & & & & & & & 0.04 & 0.15 \\
\hline Systolic BP change overnight & & & & & & & & & & 0.60 \\
\hline
\end{tabular}

^Negative value indicates a fall overnight, positive value indicates a rise.

Any $r$ value over 0.10 is significant at the 0.05 level, any $r$ value over 0.17 is significant at the 0.0001 level.

Table 4 Multiple linear regression results, modelling BP change overnight $(n=448)$

\begin{tabular}{|c|c|c|c|c|}
\hline & \multicolumn{3}{|c|}{$\%$ variance explained } & \multirow[b]{2}{*}{$\beta$ coefficient $(95 \%$ CI) } \\
\hline & Men & Women & Combined & \\
\hline \multicolumn{5}{|c|}{ Systolic BP change overnight $(\mathrm{mm} \mathrm{Hg})$} \\
\hline Mean respiratory effort (ms) & $6.5(\mathrm{p}=0.0002)$ & $4.5(\mathrm{p}=0.001)$ & $5.2(\mathrm{p}<0.0001)$ & $0.95(0.53$ to 1.37$)$ \\
\hline$>4 \% \mathrm{SaO}_{2} \mathrm{dips} / \mathrm{h}$ & $3.4(\mathrm{p}=0.009)$ & $1.6(\mathrm{p}=0.09)$ & $2.2(\mathrm{p}=0.0013)$ & $0.52(0.18$ to 0.89$)$ \\
\hline Total & 9.9 & 6.1 & 7.4 & \\
\hline \multicolumn{5}{|c|}{ Diastolic BP change overnight $(\mathrm{mm} \mathrm{Hg})$} \\
\hline$>4 \% \mathrm{SaO}_{2} \mathrm{dips} / \mathrm{h}$ & $7.1(\mathrm{p}=0.0001)$ & & $5.1(\mathrm{p}<0.0001)$ & $0.48(0.26$ to 0.70$)$ \\
\hline Mean respiratory effort (ms) & & $1.7(\mathrm{p}=0.05)$ & $1.0(\mathrm{p}=0.01)$ & $0.34(0.07$ to 0.61$)$ \\
\hline Total & 7.1 & 1.7 & 6.1 & \\
\hline
\end{tabular}

independent contribution to the changes in $\mathrm{BP}$ overnight, either systolic or diastolic. In particular, the actual BP had no predictive effect on the change in BP overnight, even when correlated singly (all p values $>0.15$ ). No significant differences were found whether the non-normally distributed variables were first logged or not $\left(>4 \% \mathrm{SaO}_{2}\right.$ dips $/ \mathrm{h}$, minimum $\mathrm{SaO}_{2}, \mathrm{BP}$ or heart rate rises/h, and snores/h). A separate analysis excluding those on hypertensive medications did not significantly alter the results. One difference emerged between men and women when analysed separatelynamely, diastolic BP change overnight in women did not seem to be affected by either $>4 \% \mathrm{SaO}_{2}$ dips/h or mean respiratory effort. The use of interactive terms, or the addition of other uncorrelated variables, did not improve the degree of fit. Table 4 shows the results of the multiple regression analysis (stepwise/ forward) by sex, indicating that $5-10 \%$ of the change in BP overnight could be accounted for by both the $>4 \% \mathrm{SaO}_{2}$ dips $/ \mathrm{h}$ and mean respiratory effort.

Although not part of this study, the dominant independent predictor of actual blood pressure, both systolic and diastolic, was the waist to height ratio, which had no predictive effect on the evening to morning changes in BP.

\section{Discussion}

This study has looked at the sleep study predictors of overnight change in blood pressure in a community population and found that both hypoxic dipping and increased respiratory effort may play a part in reducing the normal overnight fall in BP. Table 5 shows the magnitude of the overnight fall in systolic BP and its degree of dependence on the overnight respiratory effort (men and women combined). In the population quartile with the lowest overnight respiratory effort $(2.8-8.2 \mathrm{~ms})$ the overnight fall in BP averaged about $14 \mathrm{~mm} \mathrm{Hg}$, but fell only about $6 \mathrm{~mm} \mathrm{Hg}$ in those in the highest quartile (11.8-23.8 ms).

By looking at the change in BP overnight we have tried to remove many of the confounding variables that also influence both diurnal BP and sleep apnoea, which makes apportionment of independent effects very difficult. Indeed, none of the usual predictors of diurnal BP were predictors of overnight change. Furthermore, by studying the sleep variables on the same night as the BP change measurements we hoped to remove some of the dilution effects on any relationships due to the night to night variation in severity of sleep apnoea. ${ }^{34}$ On the other hand, there will have been an order effect from always measuring the evening figures first, 
Table 5 Influence of mean respiratory effort overnight on systolic and diastolic BP change overnight in men and women $(n=448)$

\begin{tabular}{|c|c|c|c|c|}
\hline & \multicolumn{4}{|c|}{ Quartiles of overnight mean respiratory effort (ms) } \\
\hline & $\begin{array}{l}\text { Quartile } 1 \\
(2.8-8.2)\end{array}$ & $\begin{array}{l}\text { Quartile } 2 \\
(8.2-9.7)\end{array}$ & $\begin{array}{l}\text { Quartile } 3 \\
(9.7-11.8)\end{array}$ & $\begin{array}{l}\text { Quartile 4 } \\
(11.8-23.8)\end{array}$ \\
\hline $\begin{array}{l}\text { Systolic } \mathrm{BP}^{\star} \text { change overnight }(\mathrm{mm} \mathrm{Hg}) \\
\text { (SD) }\end{array}$ & $\begin{array}{l}-13.6 \\
(12.7)\end{array}$ & $\begin{array}{l}-10.8 \\
(14.4)\end{array}$ & $\begin{array}{l}-7.3 \\
(11.7)\end{array}$ & $\begin{array}{l}-5.6 \\
(13.2)\end{array}$ \\
\hline $\begin{array}{l}\text { Diastolic } \mathrm{BP}^{\star} \text { change overnight }(\mathrm{mm} \mathrm{Hg}) \\
\text { (SD) }\end{array}$ & $\begin{array}{l}-5.8 \\
(8.1)\end{array}$ & $\begin{array}{l}-4.5 \\
(9.2)\end{array}$ & $\begin{array}{l}-3.0 \\
(8.0)\end{array}$ & $\begin{array}{l}-1.9 \\
(11.1)\end{array}$ \\
\hline
\end{tabular}

^ A negative value indicates a fall in BP overnight.

but this will have been the same for all subjects and should not influence other interrelationships. In addition, by using the BP just after waking we will have missed the nadir of the sleep related fall in BP and allowed other potential factors to influence the figure obtained-for example, whether a subject woke spontaneously or by alarm clock However, this should have introduced random noise into our data and there is no obvious reason why it should have produced a confounding bias.

A community population, rather than a group of clinic patients with OSA, was chosen for a variety of reasons. Young et al have shown an association between AHI and BP in a similar community sample, and found almost as much effect on BP from a low AHI $(<15)$ as from higher values, ${ }^{20}$ although this was less obvious in a later analysis. ${ }^{1}$ In addition, once severe OSA has developed, other factors such as overnight nocturia may come into play which might limit hypertension $^{21} 22$ and confound any potential relationships still further. This may be why it has been difficult to prove an extra independent effect of OSA on BP at the severe end of the spectrum where one might have thought the signal would be strongest. ${ }^{23} 24$

Although our studied group was only $36 \%$ of the original randomly selected group (41\% of those actually contactable), this is unlikely to influence the relationships discussed, although to some extent it may have biased the group away from the true population. Other potential problems revolve around the use of our new technique, pulse transit time (PTT), to estimate both respiratory effort and autonomic arousal. The experimental evidence is good that this indirect way of measuring beat to beat blood pressure can usefully measure respiratory effort and arousals. ${ }^{11-15} 1725$ In recent studies autonomic arousal indices were at least as good as conventional EEG based microarousal detection in predicting daytime sleepiness, and also its response to treatment. ${ }^{15}{ }^{16} \mathrm{~A}$ reasonable concern was that in some way blood pressure itself might affect the size of pulsus paradoxus measured by PTT during respiratory efforts, and that the relationship we have established could have been reverse causality. However, by including measures of actual systolic and diastolic BP in the multiple regression analysis, and showing that they had no predictive ability for overnight change, we are sure that we have cause and effect the right way round.

Others have shown that OSA may have a greater effect on morning BP in clinic patients than later on during the day. For example, in 611 outpatients referred for sleep laboratory investigation Hoffstein $e t a l^{6}$ showed that those with AHI values of $<10 / \mathrm{h}$ tended to have a fall in BP night to morning of about $1 \mathrm{~mm} \mathrm{Hg}$ compared with a rise of $2 \mathrm{~mm} \mathrm{Hg}$ if the AHI was $>50 / \mathrm{h}$. In a multiple regression analysis the AHI accounted for some of the variance $(7.8 \%)$ of morning mean arterial pressure. They found that AHI was more predictive of morning pressures than the desaturation indices, perhaps indicating that increases in inspiratory effort (or arousals) might be more important than the hypoxia.

Using 24 hour BP measurements, Sullivan et $a l^{27}$ and Davies et $a l^{28}$ found that patients with OSA had less of a fall in BP actually during sleep than normal subjects. Inspection of the 24 hour plots in a later paper from Sullivan's group, ${ }^{29}$ providing data from patients with OSA before and after nasal CPAP, suggests that the maximum effects of OSA during the day are seen between 08.00 and 12.00 hours, although these data were uncontrolled. In a community study from Wisconsin by Young et al 24 hour $\mathrm{BP}$ data from subjects with AHI values of $>5 / \mathrm{h}$ showed larger differences in $\mathrm{BP}$ during the first three hours after rising than those with AHI values of $<5 / \mathrm{h}$.

Thus, we are confident that in our study the smaller falls in evening to morning BP are real and are likely to be due in part to some aspect of upper airway obstruction during sleep. The novel finding is that this may be partly due to the increased inspiratory effort that OSA and its variants engender, in addition to the hypoxia, rather than to recurrent arousal- the clear cause of the transient post-apnoea rises in BP. ${ }^{5}$

Any possible mechanism for this effect of increased respiratory effort on morning BP is, of course, entirely speculative. However, it may be that, by dropping the blood pressure repeatedly throughout the night, recurrent pulsus paradoxus during partially or completely obstructed inspiratory efforts could lead to some compensatory mechanisms such as increased sympathetic tone which takes time to wear off the following morning. Certainly, diurnally increased sympathetic tone is seen in clinic patients with significant OSA. ${ }^{7}$ Alternatively, minor but prolonged rises in $\mathrm{PaCO}_{2}$ due to the inspiratory loading might contribute.

In conclusion, we suggest that some of the stimulus to any raised BP outside sleeping hours in subjects with even mild degrees of upper airway narrowing during sleep may be due to the mechanical effects of increases in inspiratory effort on blood pressure (pulsus paradoxus), in addition to any attendant hypoxic episodes.

This study was supported by a grant from the Wellcome Trust. The help and cooperation offered by the GPs and practice staff are gratefully acknowledged.

1 Young T, Peppard P, Palta M, et al. Population-based study of sleep-disordered breathing as a risk factor for hypertension. Arch Intern Med 1997;157:1746-52.

2 Young T, Finn L, Hla KM, et al. Snoring as part of a doseresponse relationship between sleep-disordered breathing and blood pressure. Sleep 1996;19:S202-5.

3 Stradling JR, Mitchell J. Reproducibility of home oximetry tracings. $\mathcal{F}$ Ambulatory Monitoring 1989;2:203-8.

4 Chediak AD, Acevedo Crespo JC, Seiden DJ, et al. Nightly variability in the indices of sleep-disordered breathing in variability in the indices of sleep-disordered breathing in
men being evaluated for impotence with consecutive night men being evaluated for impotence with
polysomnograms. Sleep 1996;19:589-92. 
5 Ali NJ, Davies RJO, Fleetham JA, et al. The acute effects of continuous positive airway pressure and oxygen administration on blood pressure during obstructive sleep apnea. Chest 1992;101:1526-32.

6 Ringler J, Basner RC, Shannon R, et al. Hypoxemia alone does not explain blood pressure elevations after obstructive apneas. F Appl Physiol 1990;69:2143-8.

7 Carlson JT, Hedner J, Elam M, et al. Augmented resting sympathetic activity in awake patients with obstructive sleep apnea. Chest 1993;103:1763-8.

8 Gribbin B, Steptoe A, Sleight P. Pulse wave velocity as a measure of blood pressure change. Psychophysiology 1976; 13:86-90.

9 Pollak $\mathrm{MH}$, Obrist PA. Aortic-radial pulse transit time and ECG Q-wave to radial pulse wave interval as indices of beat-by-beat blood pressure change. Psychophysiology 1983; 20:21-8.

10 Stradling JR, Crosby JH. Relation between systemic hypertension and sleep hypoxaemia or snoring: analysis in 748 tension and sleep hypoxaemia or snoring: analysis in 748

11 Pitson D, Chhina N, Knijn S, et al. Changes in pulse transit time and pulse rate as markers of arousal from sleep in normal subjects. Clin Sci 1994;87:269-73.

12 Pitson DJ, Stradling JR. Autonomic markers of arousal during sleep in patients undergoing investigation for obstructive sleep apnoea, their relationship to EEG arousals, respiratory events and subjective sleepiness. F Sleep Res 1998;7: 53-60

13 Brock J, Pitson D, Stradling JR. Use of pulse transit time as a measure of changes in inspiratory effort. 7 Ambulatory Monitoring 1993;6:295-302.

14 Pitson DJ, Sandell A, van den Hout R, et al. Use of pulse transit time as a measure of inspiratory effort in patients with obstructive sleep apnoea. Eur Respir f 1995;8:166974.

15 Pitson DJ, Stradling JR. Value of beat-to-beat blood pressure changes, detected by pulse transit time, in the management of the obstructive sleep apnoea/hypopnoea syndrome. Eur Respir f 1998;12:685-92.

16 Bennett LS, Langford BA, Stradling JR, et al. Sleep fragmentation indices as predictors of daytime sleepiness and nCPAP response in OSA. Am 7 Respir Crit Care Med 1998;158:778-86.
17 Argod J, Pepin JL, Levy P. Differentiating obstructive and central sleep respiratory events through pulse transit time. Am $\mathcal{F}$ Respir Crit Care Med 1998;158:1778-83.

18 Jamieson MJ, Webster J, Witte K, et al. An evaluation of the A\&D UA-751 semi-automated cuff-oscillometric sphygmomanometer. F Hypertens 1990;8:377-81.

19 Ashwell M, Cole TJ, Dixon AK. Ratio of waist circumference to height is strong predictor of intra-abdominal fat. BM7 1996;313:559-60.

$20 \mathrm{Hla}$ KM, Young TB, Bidwell T, et al. Sleep apnea and hypertension. Ann Intern Med 1994;120:382-8.

21 Warley AR, Stradling JR. Abnormal diurnal variation in salt and water excretion in patients with obstructive sleep apnoea. Clin Sci 1988;74:183-5.

22 Krieger J, Imbs JL, Schmidt $M$, et al. Renal function in patients with obstructive sleep apnea. Effects of nasal continuous positive airway pressure. Arch Intern Med 1988; 148:1337-40.

23 Millman RP, Redline S, Carlisle CC, et al. Daytime hypertension in obstructive sleep apnea. Prevalence and contributing risk factors. Chest 1991;99:861-6.

24 Hoffstein V. Blood pressure, snoring, obesity, and nocturnal hypoxaemia. Lancet 1994;344:643-5.

25 Smith RP, Argod J, Pepin J, et al. Pulse transit time: an appraisal of potential clinical applications. Thorax 1999;54: $452-8$.

26 Hoffstein V, Mateika J. Evening-to-morning blood pressure variations in snoring patients with and without obstructive sleep apnea. Chest 1992;101:379-84.

27 Wilcox I, Grunstein RR, Collins FL, et al. Circadian rhythm of blood pressure in patients with obstructive sleep apnea. Blood Pressure 1993;1:219-22.

28 Davies RJO, Crosby J, Prothero A, et al. Ambulatory blood pressure and left ventricular hypertrophy in untreated obstructive sleep apnoea and snoring, compared to matched controls, and their response to treatment. Clin Sci 1994;86:417-24.

29 Wilcox I, Grunstein RR, Hedner JA, et al. Effect of nasal continuous positive airway pressure during sleep on 24 -hour blood pressure in obstructive sleep apnea. Sleep 1993;16:539-44. 